\section{ARTICLE}

Ceri Holdsworth

\section{Office for National Statistics}

The Annual Survey of Hours and Earnings (ASHE) is the most detailed and comprehensive source of information on levels of earnings, make-up of total earnings and distribution of the earnings of individual employees.

The first few sections of this article present summary analyses (overall medians, the make up and distribution of earnings) from the results of the 2009 ASHE, comparing them with the 2008 results (and where relevant the 1997 to 2008 back series). While these figures are of interest, they can hide wide variations between different industries, occupations, regions and age groups. The concluding sections of the article give summary analyses of each of these factors.

\title{
Patterns of pay: results of the Annual Survey of Hours and Earnings 1997 to 2009
}

\section{Key points}

- In April 2009, median gross weekly earnings were $£ 489$ (for full-time UK employee jobs on adult rates whose earnings were not affected by absence), up 2.0 per cent from $£ 479$ in 2008.

- Between 2008 and 2009, the weekly earnings for full-time employees in the bottom decile grew by 3.2 per cent to $£ 271$, compared with a growth of 2.1 per cent for the top decile to $£ 971$.

- For the 2008/09 tax year, median gross annual earnings for full-time employees on adult rates who have been in the same job for at least 12 months were $£ 25,800$. For males, median gross annual earnings were $£ 28,300$ while the comparable figure for females was $£ 22,200$.

- In April 2009, median hourly earnings excluding overtime for full-time

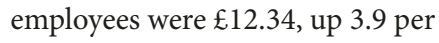
cent from $£ 11.88$ in 2008 . Women's hourly earnings were $£ 11.39$ while the comparable figure for men was $£ 12.97$.

- The stronger growth in women's hourly earnings excluding overtime compared with men's (4.3 per cent and 3.8 per cent respectively) has meant that the gender pay gap for full-time employees has decreased to 12.2 per cent from 12.6 per cent in 2008. For part-time employees, the negative gender pay difference narrowed to -2.0 per cent compared with -3.7 per cent in 2008. The gender pay comparison based on median hourly earnings excluding overtime for all employees, regardless of whether they were working on a full-time or part-time basis, decreased to 22.0 per cent from 22.5 per cent in 2008.

\section{Introduction}

- he Annual Survey of Hours and Earnings (ASHE) is ONS's most detailed and comprehensive source of information on:

- levels of earnings (for both full-time and part-time employees and for gender)

- make-up of total earnings (split between basic pay and other components)

- distribution of earnings (the extent to which they are dispersed around the median)

ASHE focuses on estimates of the median rather than the mean. The median is the value below which 50 per cent of employees fall. The median is preferred to the mean for earnings as it is less affected by extreme values and the skewed distribution of earnings data. However, estimates of the mean are still available in the annually published results.

More details on the methodology for the survey were published in November 2004 on the National Statistics website at www. statistics.gov.uk/cci/article. asp?id=985.

The first few sections of this article present summary analyses on overall medians, the make-up of earnings, the distribution of earnings and gender pay 
differences for the 2009 ASHE, comparing the analysis with the 2008 results (and where relevant with the 1997 to 2008 back series). While these estimates are of interest, they can hide wide variations between different industries, occupations, regions and age groups. The concluding sections of the article give summary analyses of each of these breakdowns and the relevant gender pay differences.

For 2004, results are available that exclude supplementary information to be comparable with the back series generated by the imputation and weighting of the 1997 to 2003 New Earnings Survey (NES) data. From 2004 to 2006, results are available on the same basis (they all have the 2004, 2005 and 2006 changes incorporated into them). The methodological changes made in 2007 have also been taken back to 2006 so that 2006, 2007, 2008 and 2009 results are comparable. This means that by producing two versions of 2004 results and two versions of 2006 results ONS is able to produce a continuous series of growth rates over this period. The survey changes introduced since 2004 are detailed in the Technical Note at the end of the article.

Both sets of 2004 and 2006 results are included in the tables accompanying this article and can be found on the National Statistics website at www.statistics.gov. uk/StatBase/Product.asp?vlnk=14123. Discontinuities are represented by a broken line in the figures.

\section{Summary results for full-time employees}

Median gross weekly earnings for full-time employees on adult rates of pay working a full week in April 2009 were $£ 489$ (see Figure 1). At $£ 531$, median gross weekly earnings of men on adult rates working on a full-time basis (whose pay for the pay period was not affected by absence) increased by 1.8 per cent over the year. This is compared with a 3.4 per cent rise for women to $£ 426$. Since 1997 , median gross weekly earnings for women working full-time have increased significantly more than for men working full-time (60.8 per cent for women compared with 48.8 per cent for men).

Median gross annual earnings of all fulltime employees on adult rates who have been in the same job for at least a year were $£ 25,800$ for the 2008/09 tax year. Median gross annual pay for men was $£ 28,300$, up 2.7 per cent from 2008 and for women was $£ 22,200$, up 3.1 per cent.

Median hourly earnings excluding overtime of all full-time employees were $£ 12.34$ in April 2009, representing an increase of 3.9 per cent since April 2008. Female employees working full-time saw an increase in median hourly earnings of 0.5 percentage points more than that of men (4.3 per cent compared with 3.8 per cent).

Since 1997 there has been a slight fall in the mean total paid hours worked per week by employees in full-time employment and for whom weekly paid hours were reported (39.0 hours in 2009 compared with 40.0 hours in 1997). In April 2009, men worked 40.1 paid hours per week and women worked 37.4 paid hours per week.

\section{Summary results for part-time employees}

Part-time employees earned a median hourly rate excluding overtime of $£ 7.83$ in April 2009, an increase of 4.4 per cent over the year. For men the increase was 6.3 per cent over the year to $£ 7.71$, while for women the increase was 4.6 per cent to $\mathfrak{£ 7 . 8 6}$. Since 1997, female employee hourly rates have remained above the levels for male employees (see Figure 2) with little change to the pay gap during this period.

There has been a slight increase in the ratio of part-time to full-time median hourly earnings excluding overtime since 1997. In 2009 median hourly earnings excluding overtime for part-time workers were 63.5 per cent of those for full-time workers (compared with 60.7 per cent in 1997). For men, part-time earnings were 59.4 per cent of full-time earnings (compared with 56.9 per cent in 1997) and for women the comparable figures were 69.0 per cent in 2009 and 68.4 per cent in 1997 (see Figure 3).

The proportion of male employees in the total workforce who worked part-time rose from 4.2 per cent to 5.7 per cent between 1997 and 2009. However, this figure is still well below the proportion of female employees working part-time, which fell from 21.2 per cent to 20.3 per cent of the total workforce over the same period. (Note that these figures are based on Labour Force

\section{Figure 1}

Median gross weekly earnings of full-time employees: by gender, ${ }^{1,2}$ April 1997 to April 2009

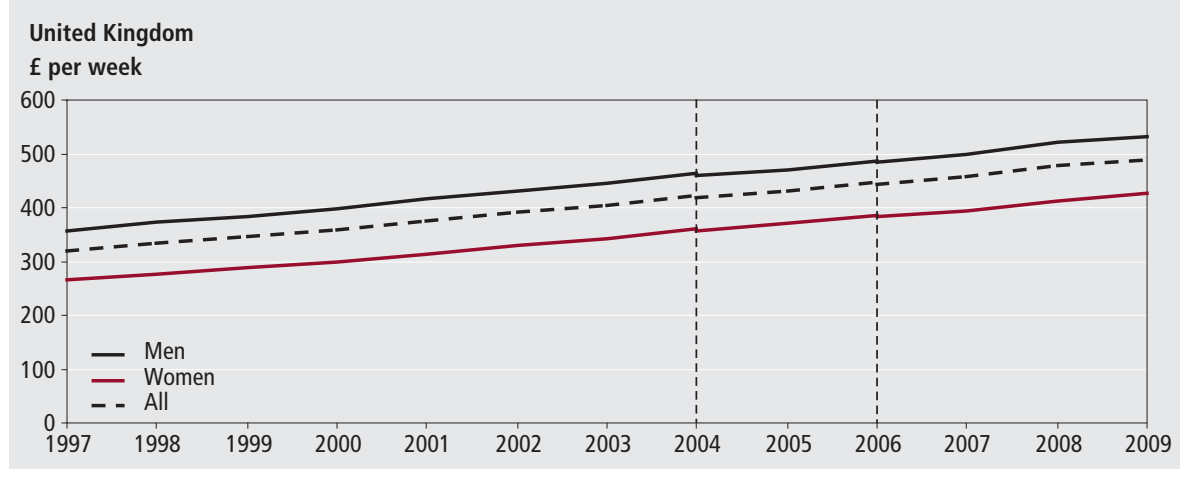

Notes:

Source: Annual Survey of Hours and Earnings

1 Full-time employees, on adult rates whose pay for the survey period was unaffected by absence.

2 Broken vertical lines represent discontinuities in 2004 and 2006 ASHE results.

\section{Figure 2}

Median hourly earnings of part-time employees: by gender, ${ }^{1,2}$ April 1997 to April 2009

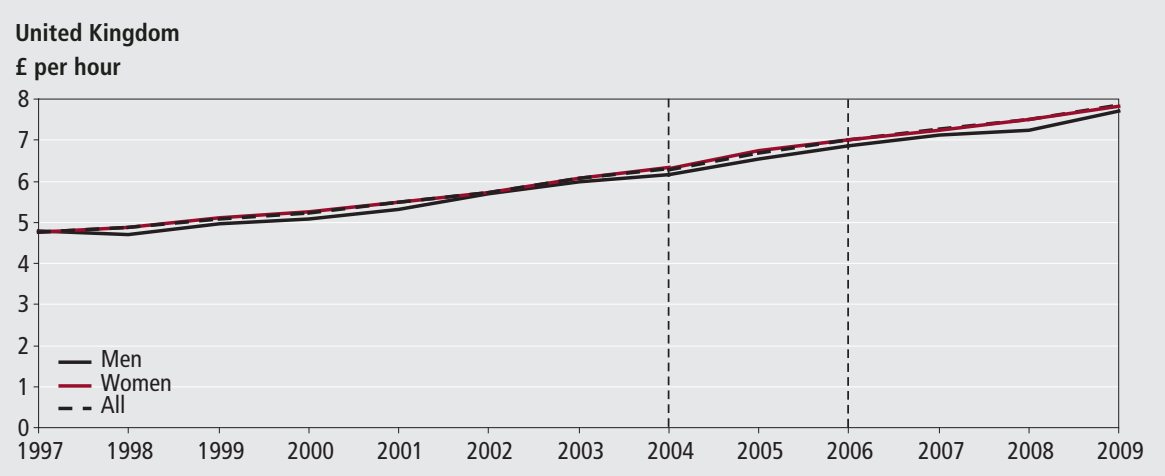

Notes:

Source: Annual Survey of Hours and Earnings

1 Hourly earnings excluding overtime for part-time employees on adult rates whose pay for the survey period was unaffected by absence.

2 Broken vertical lines represent discontinuities in 2004 and 2006 ASHE results. 


\section{Figure 3}

\section{Ratio of part-time to full-time median hourly earnings, ${ }^{1,2}$ April 1997 to April 2009}

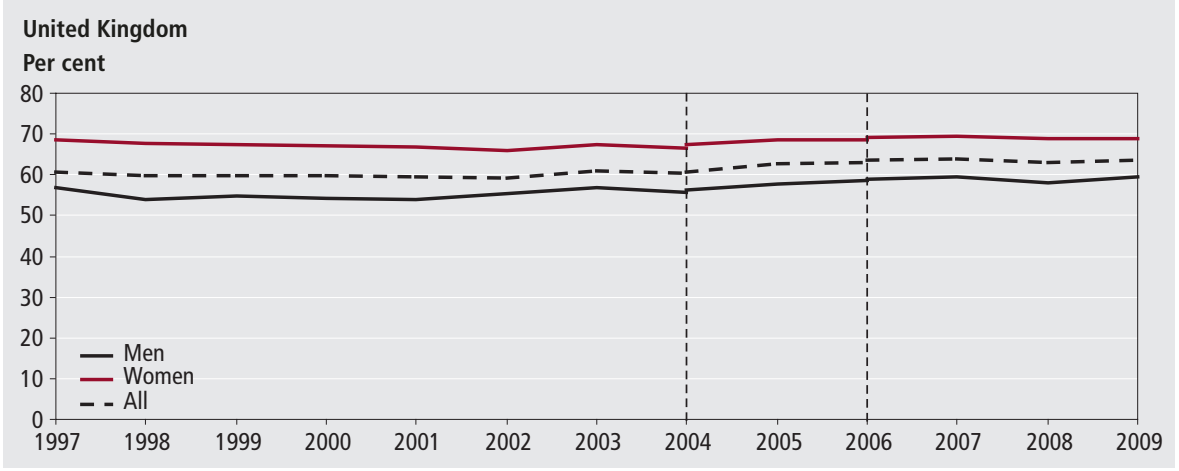

Notes:

Source: Annual Survey of Hours and Earnings

1 Hourly earnings, excluding overtime, for employees on adult rates, whose pay for the survey period was unaffected by absence.

2 Broken vertical lines represent discontinuities in 2004 and 2006 ASHE results.

\section{Figure 4}

Distribution of part-time employees: by gender and age group, ${ }^{1}$ April 2009

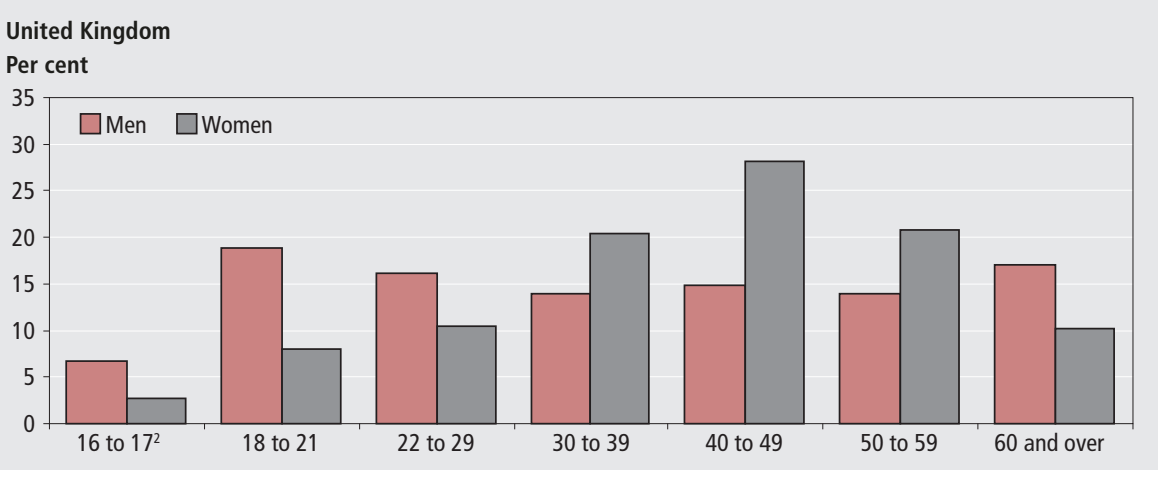

\section{Notes:}

Source: Annual Survey of Hours and Earnings

1 Part-time employees on adult rates whose pay for the survey period was unaffected by absence.

2 Results for 16 to 17 -year-olds include employees not on adult rates of pay.

Figure 5

Pay gap between women's and men's median hourly earnings, ${ }^{1,2}$
April 1997 to April 2009

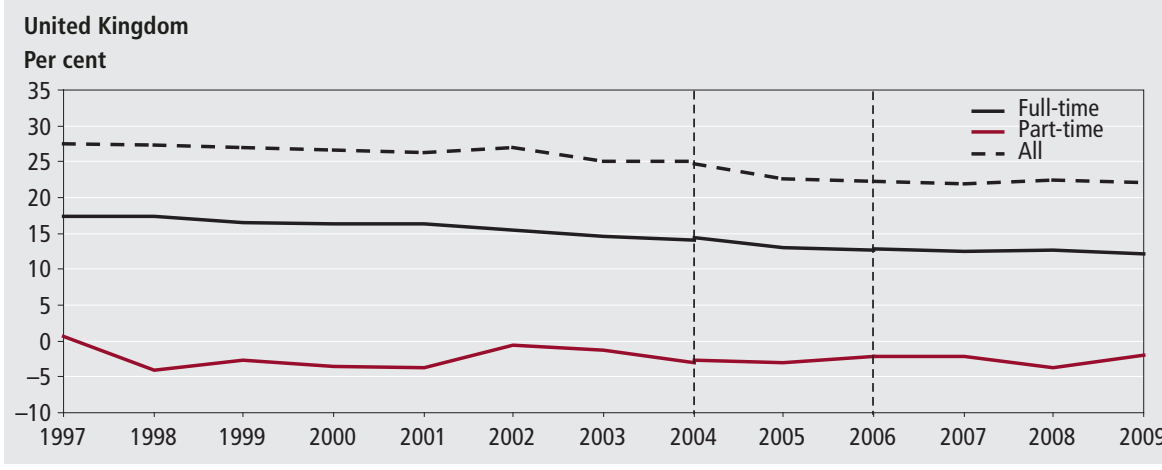

\section{Notes:}

Source: Annual Survey of Hours and Earnings

1 Hourly earnings excluding overtime for employees on adult rates whose pay for the survey period was unaffected by absence.

2 Broken vertical lines represent discontinuities in 2004 and 2006 ASHE results.

Survey (LFS) estimates of the composition of the workforce for the period April to June 2009, and have replaced the ASHE estimates that were present in the 1997-2008 Patterns of Pay Article.)
Median hourly pay for female employees working part-time is higher than that of male employees, partly due to a higher proportion of females working part-time throughout their careers. Figure 4 shows the distribution of part-time employees by gender and by age. It illustrates a higher proportion of females working part-time in the higher income age groups (aged 30 to 39,40 to 49 and 50 to 59). The proportion of males working part-time is higher in the younger age groups as well as the 60 and over age group.

\section{Pay differences between men and women}

ONS recently reviewed the way it presents gender pay statistics. The review concluded that there was no single measure which adequately dealt with the complex issue of measuring the differences in men's and women's pay. ONS now highlights the following measures:

- all female employees' median pay compared with all male employees' median pay

- female full-time employees' median pay compared with male full-time employees' median pay

- female part-time employees' median pay compared with male part-time employees' median pay

ONS prefers to use hourly earnings excluding overtime and focuses on estimates of the median. Including overtime can skew the results because men work relatively more overtime than women.

For full-time employees, hourly earnings excluding overtime were $£ 11.39$ for women (on adult rates whose pay for the pay period was unaffected by absence) and $£ 12.97$ for men. This has resulted in the gender pay gap narrowing in 2009 to 12.2 per cent, down from 12.6 per cent in 2008 (see Figure 5). The gender pay gap has therefore fallen by around five percentage points (from 17.4 per cent) for full-time employees from 1997 to 2009, meaning that the gender pay gap has narrowed by more than a quarter in the 12 years since 1997.

Median hourly earnings excluding overtime for women working part-time are higher than those of men working parttime. Men's hourly earnings were $£ 7.71$, up 6.3 per cent from $£ 7.25$ in 2008 , compared with women's hourly earnings of $£ 7.86$, an increase of 4.6 per cent from $£ 7.51$ in the previous year. The negative gender pay difference for part-time employees has therefore narrowed to -2.0 per cent from -3.7 per cent in 2008.

The gender pay difference based on median hourly earnings for all employees decreased to 22.0 per cent from 22.5 per cent in 2008 , meaning that the gender pay 
gap has again narrowed by around five percentage points (from 27.5 per cent) for all employees between 1997 and 2009.

Although ONS's headline estimates of gender pay differences are based on median hourly earnings, mean hourly earnings provide a useful supplementary measure and as such are provided as a comparison to estimates of the median gender pay gap. The differences between median and mean gender pay gaps reflect the extent to which high earners skew the earnings distribution.

The gender pay difference for mean hourly earnings excluding overtime is wider than that for median earnings and has fallen from 20.7 per cent to 16.4 per cent for full-time employees between 1997 and 2009 (see Figure 6). Men's mean hourly earnings were $£ 16.07$, up 2.8 per cent from $£ 15.63$ in 2008 . Women's mean hourly earnings increased by 4.0 per cent to $£ 13.43$ compared with $£ 12.92$ in 2008 . The mean gender pay difference of 16.4 per cent for full-time employees was therefore at its narrowest in 2009 since the series was introduced in 1997.

In contrast with the median measure, mean hourly earnings for part-time employees' were lower for women than for men. Nevertheless, the gender pay gap based on mean hourly earnings also decreased to 13.2 per cent, down from 15.2 per cent in 2008.

The gender pay difference based on the mean for all employees also decreased in 2009 to 20.2 per cent from 21.3 per cent in the previous year.

Although median and mean hourly pay excluding overtime provide a useful comparison of men's and women's earnings, they do not reveal differences in rates of pay for comparable jobs. This is because such measures do not highlight the different employment characteristics of men and women, such as the proportion of each gender in different occupations and their length of time in jobs.

\section{The make-up of earnings}

ASHE splits gross weekly earnings into four components: overtime payments, payments by results/incentive payments (such as bonuses), premium payments for shift work, and the residual - which includes basic pay and allowances. The first three components vary quite considerably by type of worker.

The 2005 ASHE questionnaire introduced a discontinuity in the makeup of gross weekly earnings regarding payments by results/incentive payments.
For comparability, this change was also applied to 2004 results. ASHE results for 2004 to 2009 include incentive payments paid and earned in the pay period, but exclude payments made less often than every pay period. As a result of this change in definition, there are a lower proportion of payments by results for these years than for earlier years. Because of this, the amount of payments by results earned in the pay period is understated. However, the estimates are improved because the new definition results in greater consistency, as the data reported will not depend on the return date of the questionnaire or when bonuses are paid, as in previous years.

The proportion of additional payments of mean gross weekly earnings for male employees working full-time was higher than that of their female counterparts over the period 1997 to 2009. In 2009 male employees earned $£ 40$ additional payments which accounted for 6.2 per cent of their total pay, whereas women's additional payments (£16) accounted for just 3.2 per cent of their total pay.

In 2009 mean overtime payments for full-time employees were $£ 16.50$ per week, down from $£ 19.70$ in 2008 . Mean payments by results/incentive payments decreased from $£ 10.80$ in 2008 to $£ 8.30$ in 2009 , the lowest since the introduction of this measurement in 2000 .

Shift premium payments were $£ 5.90$ in 2009 , down from $£ 6.10$ in the previous year. Historically, shift premium payments have fluctuated between $£ 5.40$ and $£ 6.10$ since 2000 .

\section{The distribution of earnings}

Figure 7 displays the distribution of gross weekly earnings among full-time employees for the years 1997 to 2009 . The median level of gross full-time weekly earnings in 2009 was $£ 489$ per week. This is lower than the mean $(\mathfrak{E 5 8 7 )}$ since the latter is boosted by

\section{Figure 6 \\ Pay gap between women's and men's mean hourly earnings, ${ }^{1,2}$ April 1997 to April 2009}

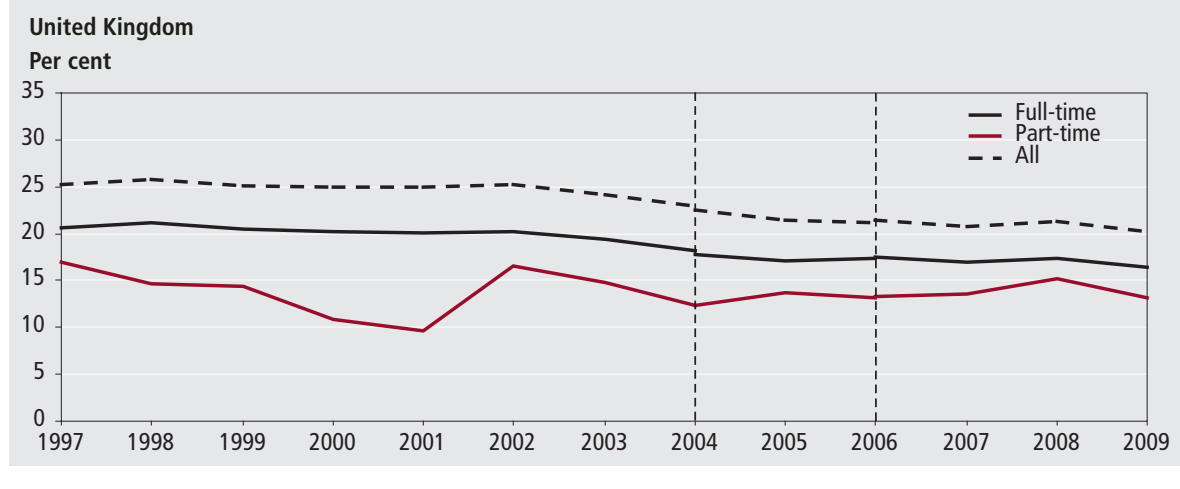

Notes:

Source: Annual Survey of Hours and Earnings

1 Hourly earnings excluding overtime for employees on adult rates whose pay for the survey period was unaffected by absence.

2 Broken vertical lines represent discontinuities in 2004 and 2006 ASHE results.

\section{Figure 7}

Distribution of gross weekly earnings for full-time employees, ${ }^{1,2}$ April 1997 to April 2009

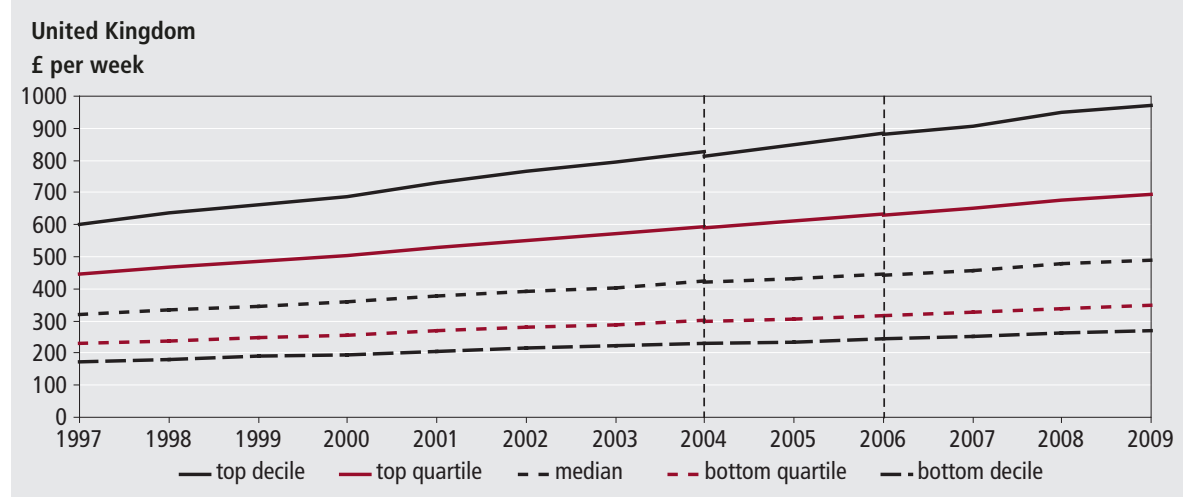

Notes:

Source: Annual Survey of Hours and Earnings

1 Full-time employees on adult rates whose pay for the period was unaffected by absence.

2 Broken vertical lines represent discontinuities in 2004 and 2006 ASHE results. 


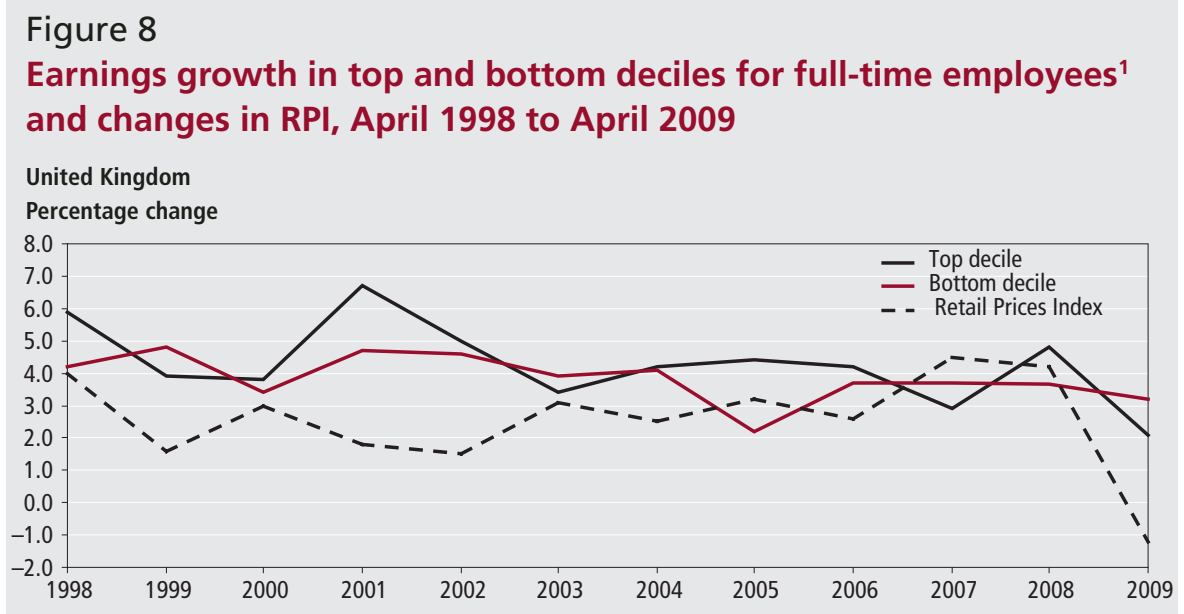

Note:

Source: Annual Survey of Hours and Earnings 1 Full-time employees on adult rates whose pay for the survey period was unaffected by absence.

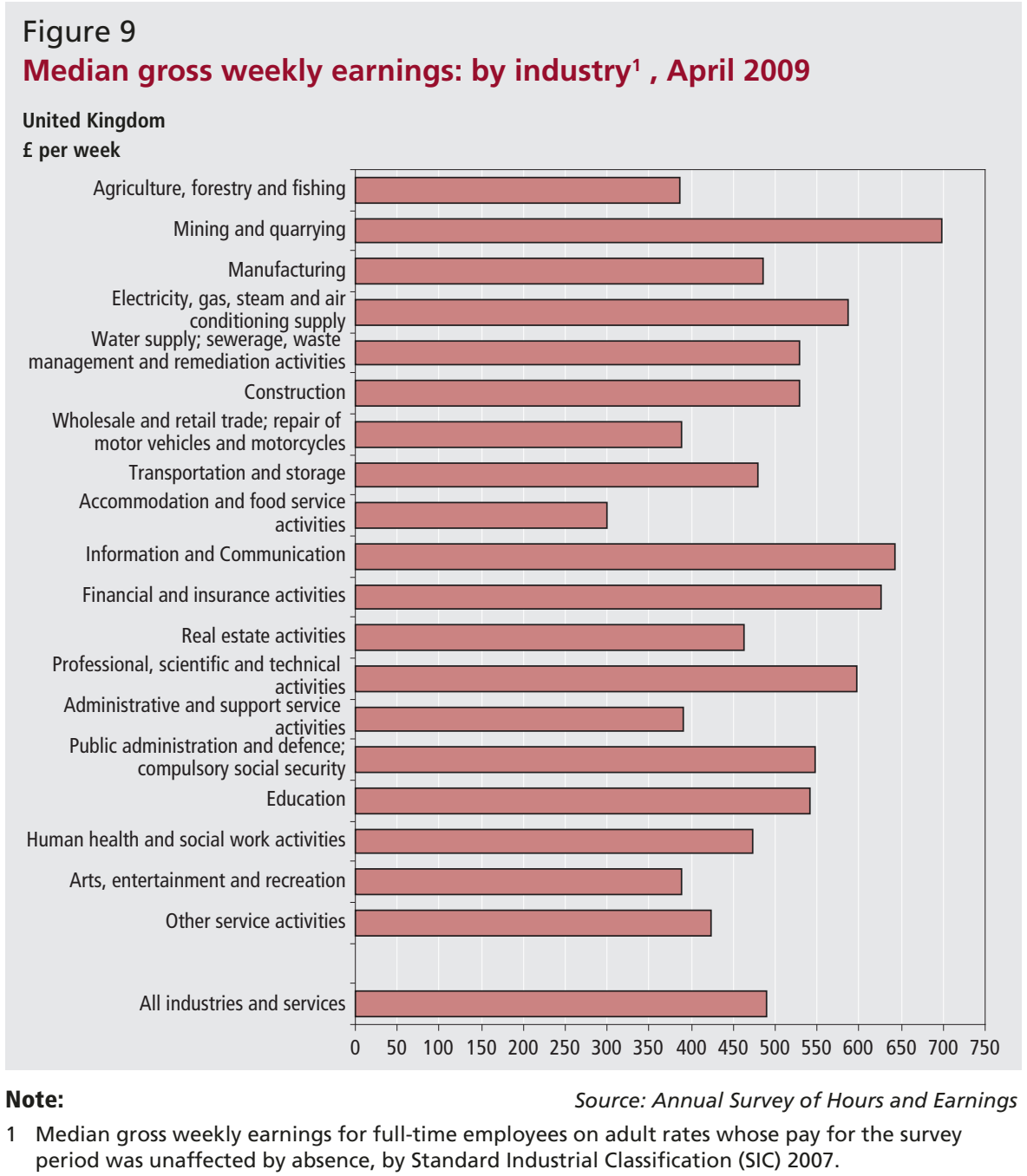

the number of people at the top end of the distribution with extremely high earnings. For 2009, at the bottom of the distribution, a tenth of full-time employees earned less than $£ 271$ per week, whereas at the other end of the scale a tenth earned more than $£ 971$ per week. The ratio of the highest to the lowest decile for gross weekly earnings (3.6 in April 2009) gives a measure of the distribution of weekly pay. This measure has by 52.8 per cent against a bottom decile increase of 49.8 per cent.

Figure 8 shows the patterns of growth in the top and bottom deciles of gross weekly earnings for full-time employees and for the Retail Prices Index (RPI) since 1997. The RPI is the most familiar general purpose domestic measure of inflation in the UK. Between April 2008 and April 2009 the rates of growth have fallen for all 3 series, but the RPI has shown negative growth of -1.2 per cent over this period. This differs from both the 2007 and 2008 results, where the growth in the RPI increased above the growth in the bottom decile of the earnings distribution.

\section{Results by industry}

For ASHE, the Standard Industrial Classification (SIC) 2007 has replaced the Standard Industrial Classification (SIC) 2003 as the classification used to present earnings statistics. The first year available on the new basis is 2008. From 2009 onwards the figures will be presented on the SIC 2007 basis only.

Median gross weekly earnings for full-time employees in April 2009 were highest in the mining and quarrying sector at $£ 698$ (see Figure 9). This was $£ 54$ per week more than the second highest, the information and communication sector. Over the period 1997 to 2009 financial and insurance activities has also featured as one of the highest median gross weekly earnings sectors (this was previously classified as the financial intermediation sector under SIC 2003). The weekly earnings for the mining and quarrying sector are boosted by longer paid hours worked by employees in these sectors relative to other sectors. The accommodation and food service activities sector has the lowest median gross weekly earnings. At $£ 299$, full-time employees’ earnings were some $£ 88$ per week lower than the median for agriculture, forestry and fishing (the second lowest paid).

In 2009 median gross annual earnings of $£ 35,600$ for the mining and quarrying sector were more than double that of the accommodation and food service activities sector, which was the lowest paid with earnings of $£ 15,900$. The accommodation and food service activities sector contains the same industries that were previously categorised under the hotels and restaurants sector for SIC 2003. If mean annual earnings are considered instead of median, gross annual earnings for the financial and insurance activities sector were significantly higher than that of any other sector. This is 
because of the skewed effect of extremely high earners on the earnings distribution.

The financial and insurance activities sector had the highest median hourly earnings excluding overtime for fulltime employees (£17.38), followed by the information and communication sector (£16.73). Median hourly earnings excluding overtime for the accommodation and food service activities sector were $£ 7.10$, once again lower than the agricultural, forestry and fishing sector (£8.24).

Part-time median hourly earnings excluding overtime were highest in the financial and insurance activities sector $(£ 10.73)$ and lowest in the accommodation and food service activities sector (£5.75). These are amongst the top and bottom earners for full-time employees.

The broad industrial groupings described above can hide substantial variation within the sectors. ASHE however, allows more detailed industrial analyses. For example, it is possible to identify the highest and lowest paid industry divisions (two-digit Standard Industrial Classification (SIC) 2007). Such analyses reveal that, in addition to those employees noted earlier within the mining and quarrying, financial and insurance activities, and information and communication sectors, full-time employees involved in the extraction of crude petroleum and natural gas, manufacture of coke and refined petroleum products and mining of coal and lignite, were among the highest paid per week in April 2009.

Various branches of the manufacturing and the retail sectors make up much of the ten lowest paid industries. Accommodation and food service activities was the lowest paid sector of all.

For full-time employees, the largest gender pay difference (based on median hourly earnings excluding overtime) was for the financial and insurance activities sector at 38.4 per cent. This was also the case for all employees, regardless of whether they worked on a full-time or part-time basis, where the gender pay comparison for the financial and insurance activities sector was 42.2 per cent. For part-time employees the gender pay gap was largest at 36.5 per cent in the education sector.

\section{Public and private sector earnings}

The gap between private and public sector median earnings for full-time employees showed a slight increase in April 2009. Private sector median gross weekly earnings were $£ 465$, up 1.0 per cent from 2008 . For the public sector the comparable figure was $£ 539$, up 3.1 per cent (see Figure 10).

It is important to note that ASHE includes breakdowns by public and private sector according to the legal status of the employers. Between 2008 and 2009 Lloyds Banking Group, the Royal Bank of Scotland Group and HBOS PLC were reclassified from the private sector to the public sector. Interpretation of public / private sector movements is therefore more difficult between 2008 and 2009 than in previous years. If these banks were reclassified back into the private sector for 2009, the growth rates in the public and private sectors would be 2.7 per cent and 1.6 per cent respectively, resulting in a difference in growth rates between the sectors of 1.1 per cent rather than 2.1 per cent in 2009.

Public sector mean gross weekly earnings (at $£ 605$ ) were also higher than that of the private sector (at $\mathfrak{E 5 8 1}$ ). As with gender pay, the difference in gross weekly earnings does not reveal differences in rates of pay for comparable jobs. This is due to the types of occupations in the public and private sector being quite different.

Gender pay differences vary between the public and private sectors, depending on whether the employee is in full-time or part-time employment (see Figure 11). For full-time employees the gender pay gap in the public sector (based on median hourly earnings excluding overtime) is 11.6 per cent. The comparable figure for the private sector is 20.8 per cent. When considering part-time employees, the gender pay differences in the public and private sectors are 18.3 per cent and 0.4 per cent respectively. Gender pay differences for all employees (regardless of whether they are full-time or part-time) are 21.0 per cent in the public sector and 28.8 per cent in the private sector.

\section{Results by occupation}

ASHE 2009 data for occupation is coded to Standard Occupation Classification (SOC) 2000 which was introduced in 2002. Before then SOC 1990 was used.

\section{Figure 10}

Median gross weekly earnings for full-time employees: by public/ private sector, ${ }^{1,2}$ April 1997 to April 2009

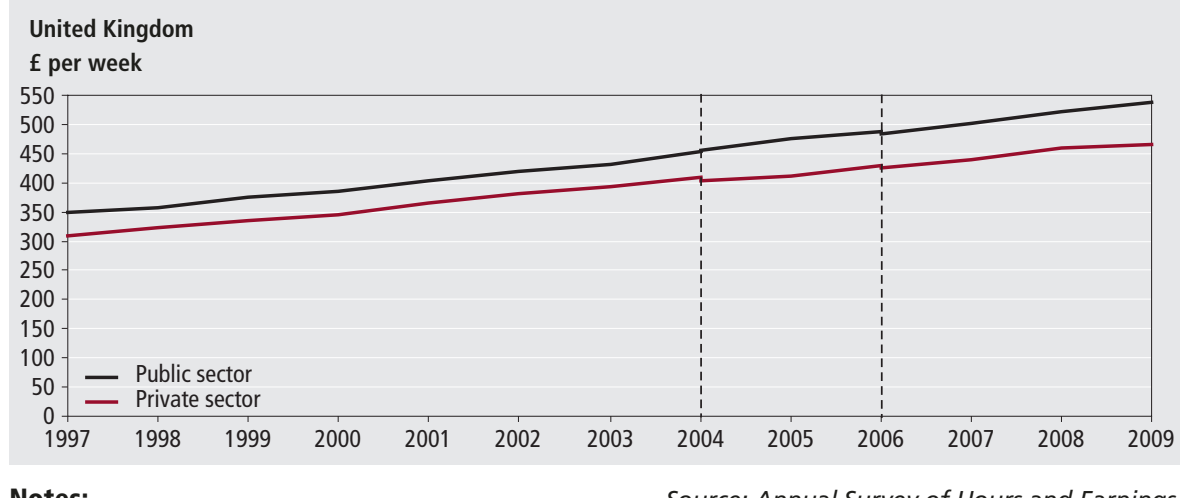

Notes:

Source: Annual Survey of Hours and Earnings

1 Full-time employees on adult rates whose pay for the period was unaffected by absence.

2 Broken vertical lines represent discontinuities in 2004 and 2006 ASHE results.

\section{Figure 11}

Pay gap between women's and men's hourly earnings: by public/ private sector, ${ }^{1}$ April 2009

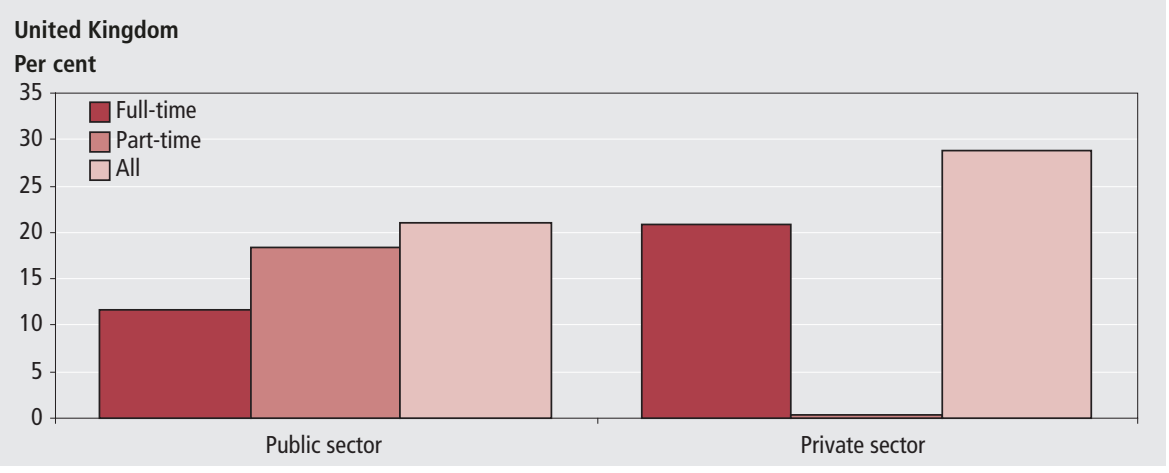

Note:

Source: Annual Survey of Hours and Earnings

1 Hourly earnings excluding overtime for employees on adult rates whose pay for the survey period was unaffected by absence. 


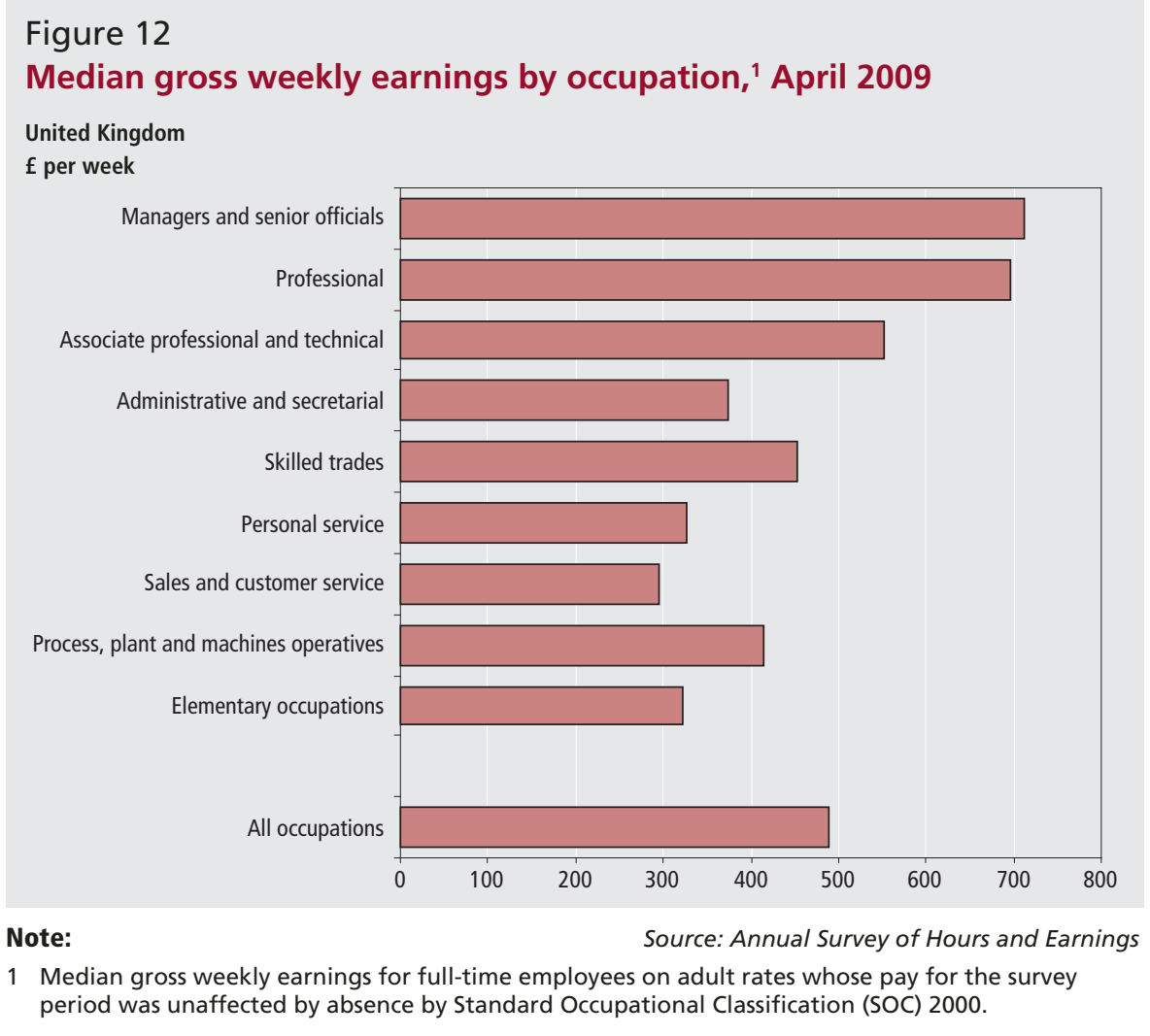

Figure 13

Pay gap between women's and men's median hourly earnings: by occupation, ${ }^{1}$ April 2009

United Kingdom

Per cent

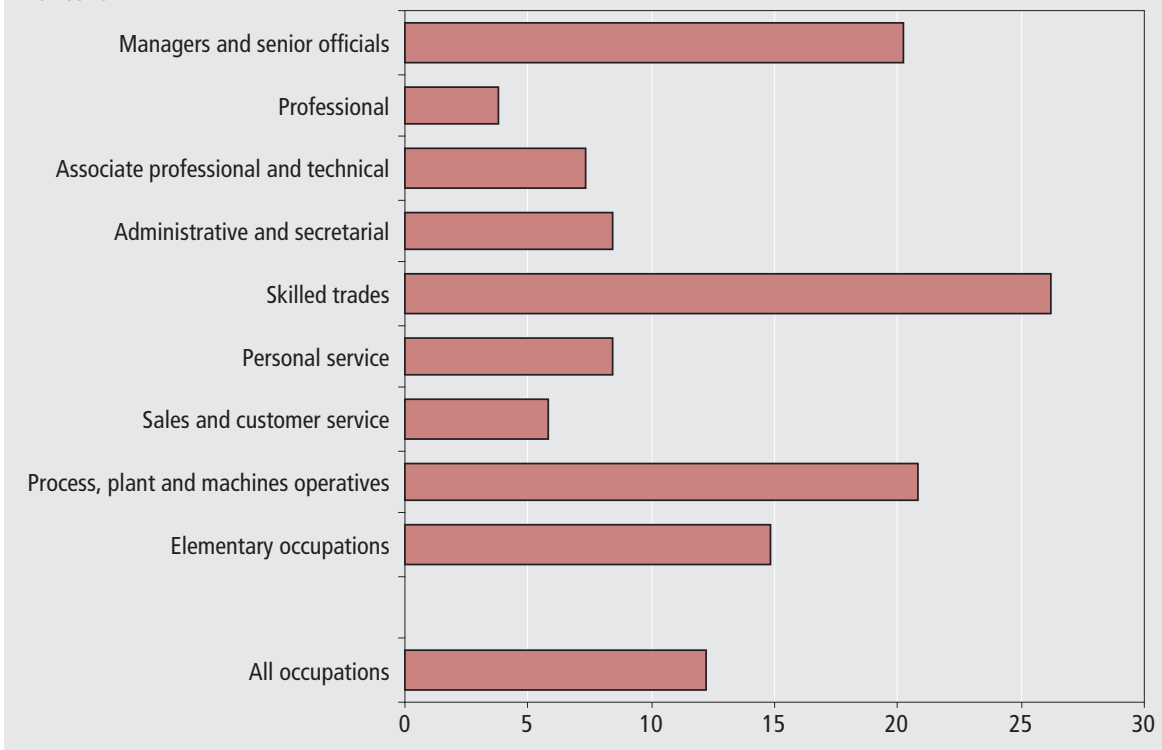

Note:

Source: Annual Survey of Hours and Earnings

1 Median hourly earnings excluding overtime for full-time employees on adult rates whose pay for the survey period was unaffected by absence by Standard Occupational Classification (SOC) 2000

The occupational major group (as defined within SOC 2000) with the highest median gross weekly earnings for fulltime employees was managers and senior officials at $£ 713$ (see Figure 12). Sales and customer service occupations were, as for the years since the introduction of SOC 2000, the lowest paid median gross weekly major group at $£ 296$ per week for full-time employees. This major group includes occupations that are generally acknowledged to be low-paid such as retail cashiers and check-out operators, and market and street traders and assistants. In April 2009 the increase in median gross weekly earnings was highest for administrative and secretarial occupations (4.1 per cent). For process, plant and machine operatives, median gross weekly earnings decreased by 0.3 per cent.

As for median gross weekly earnings, managers and senior officials had the highest median gross annual salary

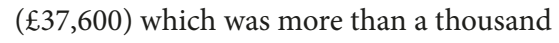
pounds higher than that for professional occupations. Similarly, sales and customer service occupations also had the lowest median gross annual salary at $£ 15,300$.

Apart from 2005, managers and senior officials had the highest median annual earnings and median gross weekly earnings since SOC 2000 was introduced in 2002. This can be explained because the managers and senior officials group receive higher annual incentives and also work longer paid hours per week than full-time employees in the professional occupations group, who had the highest median hourly earnings excluding overtime (£19.49). This was nearly a pound higher than the median for managers and senior officials ( $£ 18.64$ ), the second most highly paid major group on an hourly basis. Professional occupations have had the highest median hourly earnings excluding overtime since the introduction of SOC 2000.

In the 2009 survey, the highest paid unit group occupation (four-digit Standard Occupation Classification 2000) for fulltime employees was directors and chief executives of major organisations, with median gross weekly earnings of $£ 1,831$. The next highest paid occupation was aircraft pilots and flight engineers with median gross weekly earnings of $£ 1,302$ per week. With median gross weekly earnings of $£ 237$, waiters and waitresses were the lowest paid of all full-time employees on adult rates of pay.

With median hourly earnings excluding overtime of $£ 37.55$, medical practitioners were the highest paid part-time employees. The lowest at $£ 5.73$ were waiters and waitresses, bar staff and road sweepers. Interestingly, $£ 5.73$ is the national minimum rate for those aged 22 and over.

Figure 13 shows the median gender pay differences for 2009 broken down by the Standard Occupation Classification (SOC) 2000 major occupation groups for fulltime employees. The median gender pay gap (based on hourly earnings excluding overtime) for full-time employees is narrowest for professional occupations (3.8 per cent) and widest for skilled trades occupations (26.2 per cent).

There are large variations in the gender pay gap for part-time employees broken down by SOC 2000 major classification. In 2009, the median gender pay gap is 
widest for skilled trades occupations (22.7 per cent). The gender pay difference for associate professional and technical occupations, administrative and secretarial occupations, and elementary occupations are negative ( -6.5 per cent, -6.2 per cent and -3.0 per cent respectively), where women's hourly earnings excluding overtime are higher than those of men. For sales and customer service occupations the gender pay gap was 0.0 per cent.

For all employees, regardless of whether they work on a full-time or part-time basis, the gender pay difference is again widest for skilled trades occupations (31.2 per cent). The narrowest gap, as for full-time employees, is for professional occupations (2.4 per cent).

\section{Results by region}

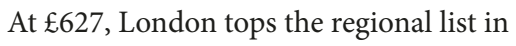
terms of median gross weekly earnings for full-time employees in April 2009. This was more than one hundred pounds above the next highest, the South East. London's high levels of pay are largely due to the fact that a high proportion of its labour force is employed in higher-paying industries and occupations, and also because many employees are entitled to allowances for working in the capital. The North East (with median full-time gross weekly earnings of $£ 436$ ) was at the bottom of the regional list with Northern Ireland (at $£ 439$ ) and Wales (at $£ 441$ ) only slightly higher. These figures can be compared with median gross weekly earnings for full-time employees at UK level, which were $£ 489$.

Employees in Northern Ireland received the largest increases in median gross weekly earnings ( 5.1 per cent to $£ 439$ ).

Since 1997 similar patterns were observed for median gross annual pay and median hourly pay excluding overtime, with London topping the list followed by the South East. The North East, Wales and Northern Ireland have the lowest pay levels across the regions.

It should be noted that earnings comparisons take no account of different price levels between regions and therefore do not indicate differences in the standard of living. Neither do they take account of the different mix of occupations and therefore cannot be used to claim that pay for like work is different. A region could have a lower level of median earnings than another if it has a higher proportion of employees in industries or occupations with relatively lower earnings.

In the UK, the gender pay gap (when measured using median hourly earnings excluding overtime for full-time employees) was 12.2 per cent. The largest gender pay gap was 16.1 per cent in the South East region and the smallest in Northern Ireland at 3.5 per cent. Over the period 1997 to 2009 , the largest reduction in the gender pay difference was in Northern Ireland (16.5 per cent to 3.5 per cent) and the smallest was in London (15.1 per cent to 13.3 per cent). Figure 14 illustrates the gender pay gap for median hourly earnings excluding overtime for the four home countries.

\section{Results by age group}

In 2009, median gross weekly earnings for full-time employees climbed steadily with age to reach a maximum of $£ 551$ for those aged 40 to 49 and declined thereafter. However, if the median earnings of men and women are considered separately, then women's earnings peaked earlier than those of men. This pattern is repeated over the period 1997 to 2009. Median gross weekly earnings of women working part-time climbed with age to reach a maximum of $£ 498$ for those aged 30 to 39 . Men’s median gross weekly earnings for full-time employees reached their maximum of $£ 606$ for those aged 40 to 49 (see Figure 15).

The largest increase in median gross weekly earnings between April 2008 and April 2009 was recorded for full-time employees aged 18 to 21 and also aged 60 and over, whose weekly earnings both increased by 2.3 per cent to reach $£ 278$ and $£ 447$ respectively.

Figure 16 shows the median gender pay differences by age group. The gender pay difference (based on median hourly earnings excluding overtime for full-time employees) was particularly small for employees in the 18 to 21 age group (1.7 per cent) and 22 to 29 age group ( 0.7 per cent) and was actually negative for 16 to 17-year-olds (-12.6 per cent). The gender pay gap then increased and peaked in those aged 40 to 49 (18.4 per cent) and remained at a high level in the 50 to 59 age group

\section{Figure 14}

\section{Pay gap between women's and men's earnings: by country, ${ }^{1,2}$ April 1997 to April 2009}

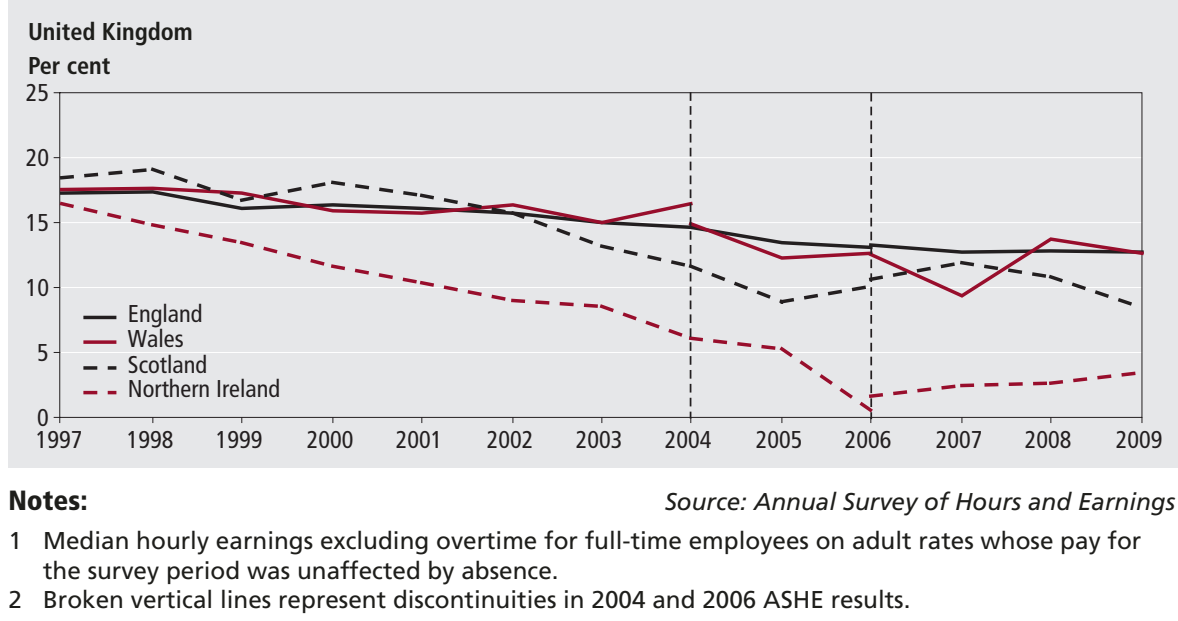

2 Broken vertical lines represent discontinuities in 2004 and 2006 ASHE results.

\section{Figure 15}

Median gross weekly earnings: by gender and by age group, ${ }^{1}$ April 2009

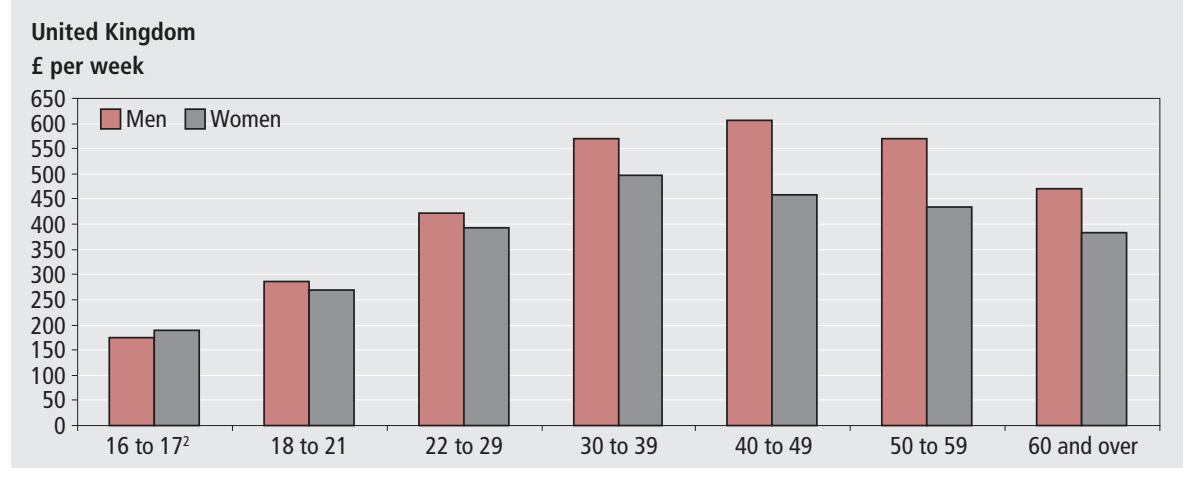

Notes:

Source: Annual Survey of Hours and Earnings

1 Full-time employees on adult rates whose pay for the survey period was unaffected by absence.

2 Results for 16 to 17 -year-olds include employees not on adult rates of pay. 


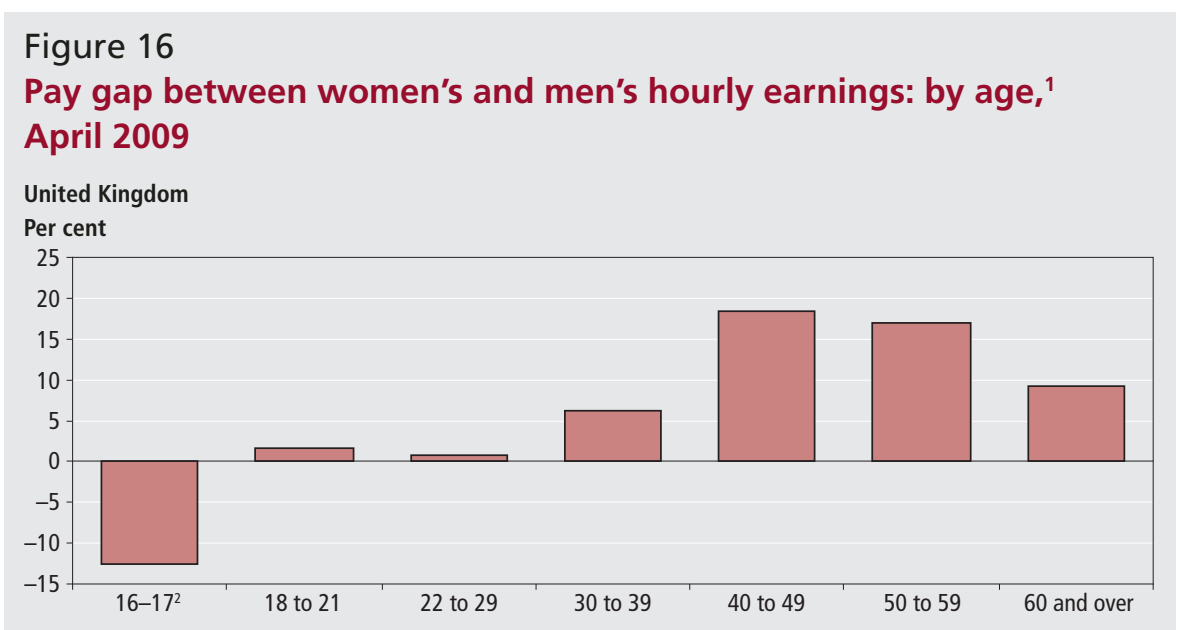

Notes:

Source: Annual Survey of Hours and Earnings

1 Hourly earnings excluding overtime for full-time employees on adult rates whose pay for the survey period was unaffected by absence

2 Results for 16 to 17-year-olds include employees not on adult rates of pay

(16.9 per cent). This can be explained by the fact that some female employees take a break from the labour market (for example to have children). When they then return to work, some of their male counterparts (those in the same age group) may have been promoted and as such could have progressed to a higher level of earnings.

Gender pay differences for part-time employees and all employees (regardless of whether they work on a full-time or parttime basis) are similar to the results for fulltime employees with the gender pay gap being greatest in the 40 to 49 age group at 23.7 per cent and 29.5 per cent respectively.

\section{Comparisons with the Average Earnings Index and Average Weekly Earnings indicators}

Each month ONS also collects information on earnings from the Monthly Wages and Salaries Survey, used to construct the Average Earnings Index (AEI) and Average Weekly Earnings (AWE). This survey asks 9,000 employers to provide information about total pay and numbers of employees, but does not ask more detailed questions such as the gender and occupations of their staff. On 26 November 2009, the UK Statistics Authority accredited the Average Weekly Earnings (AWE) indicators as National Statistics. The AWE is now ONS's lead measure of shortterm earnings, having replaced the AEI in the Labour Market Statistical Bulletin from January 2010 onwards.

The AEI is used to provide an estimate of the growth in earnings per head, while the AWE is used to produce estimates of both growth and levels of pay.

The AWE, AEI and ASHE are therefore not directly comparable on all measures of earnings. The closest measure that can be derived and compared for these surveys is for mean gross weekly pay. From 2009 onwards comparisons will only be made between ASHE and AWE. In the year to April 2009, the ASHE estimate of mean gross weekly pay for all employees (regardless of whether they were full-time or part-time) was $£ 481$, up 1.6 per cent on the previous year. The comparable estimate from the AWE was $£ 444$, also up 1.6 per cent from April 2008. For the private sector, the ASHE estimate of mean gross weekly pay for all employees was $£ 482$, while the AWE estimate was $£ 442$. For the public sector, the estimates were $£ 491$ for ASHE and $£ 450$ for AWE.

\section{Low pay jobs}

In April 2009 the number of UK jobs paid below the national minimum wage was 242,000 , accounting for 0.9 per cent of all jobs in the labour market. The estimate was produced using a methodology based solely on ASHE, which replaced NES.
There were three rates for the national minimum wage in April 2009: one for those aged 16 and 17 ( $£ 3.53$ per hour), one for those aged 18 to 21 ( $£ 4.77$ per hour) and one for those aged 22 and over ( $\$ 5.73$ per hour).

The number of jobs paid below the national minimum wage were:

- 14,000 jobs (4.1 per cent) held by those aged 16 to 17

- 44,000 jobs (2.6 per cent) held by those aged 18 to 21

- 184,000 jobs ( 0.8 per cent) held by those aged 22 and over

People in part-time work were more than twice as likely as people in full-time work to be paid less than the minimum wage, with 1.5 per cent of part-time jobs and 0.7 per cent of full-time jobs falling below the minimum wage. Jobs held by women were more likely to fall below the minimum wage than jobs held by men (1.1 per cent compared with 0.8 per cent). This was primarily due to the greater number of women in part-time jobs.

It is important to note that these estimates do not measure non-compliance with the National Minimum Wage legislation. ASHE does not indicate whether individuals fall into a category that is exempt from the legislation, such as apprentices or new trainees.

\section{SURVEY DETAILS}

Tables accompanying this article are available at

www.statistics.gov.uk/StatBase/Product. asp?vlnk=14123

\section{CONTACT}

For further information, please contact: Earnings helpdesk,

Room 1.264,

Office for National Statistics,

Cardiff Road,

Newport NP10 8XG.

ه earnings@ons.gov.uk

C 01633456120 


\section{TECHICAL NOTE}

\section{Survey details}

The Annual Survey of Hours and Earnings (ASHE) is based on a sample of employee jobs taken from HM Revenue \& Customs PAYE records. Information on earnings and paid hours is obtained in confidence from employers. It does not cover the self-employed nor does it cover employees not paid during the reference period. In 2009, the information related to the pay period which included 22 April. The 2009 ASHE is based on approximately 177,000 returns.

ASHE replaced the New Earnings Survey (NES) as ONS's main source of information on the distribution of earnings. Articles describing the ASHE methodology and the impact of its introduction on 1997 to 2004 data are available on the National Statistics website at www. statistics.gov.uk/StatBase/Product.asp?vlnk=13101. The main differences between ASHE and NES are:

- ASHE results are weighted to the number of jobs given by the Labour Force Survey

- ASHE imputes for item non-response

- The coverage of employees for ASHE is greater than that of NES

- The median replaces the mean as the headline statistic. The median is the value below which 50 per cent of employees fall. It is preferred over the mean for earnings data as it is less influenced by extreme values and because of the skewed distribution of earnings

\section{Changes in 2004}

Since 2004, survey supplementary information has been collected to improve coverage and make the survey more representative. This includes employees who have either changed or started new jobs between sample selection from HM Revenue \& Customs records and the survey reference period in April.

\section{Changes in 2005}

A new questionnaire was introduced for the 2005 survey. This questionnaire brings significant improvement to the quality of the results. More details on the impact of introducing the new questionnaire can be found at

www.statistics.gov.uk/cci/article. asp? $i d=1294$

Changes to the wording and definitions mean that some of the information requested from respondents will differ from that supplied in past surveys. The introduction of the pay 'for other reasons' question has resulted in the inclusion of earnings information which may not have been collected in the past. Results for 2004 including supplementary information have been reworked to allow for this missing pay. For more details on the methodology involved in estimating pay for other reasons see the National Statistics website at www.statistics.gov.uk/cci/article.asp?id=1299

Also the definition of incentive/bonus pay changed for 2005 to only include payments that were paid and earned in April. This brings the definition more in line with that used in the Average Earnings Index (AEI) and will result in greater consistency of ASHE results. Results for 2004 including supplementary information have been reworked to exclude irregular bonus/ incentive payments to make them consistent with results from 2005 onwards. The adjustments made to the 2004 data in order to produce estimates comparable with the 2005 data also had an impact on the gap between public and private sector earnings. The changes on the questionnaire were the exclusion of incentive payments paid outside the pay period and the inclusion of pay for other reasons. The exclusion of incentive payments paid outside the pay period pulls down the private sector estimates more than the public sector estimates because private sector employees receive a higher proportion of incentive pay than public sector employees. Also, public sector employees receive greater proportions of pay for other reasons. Therefore, public sector estimates increased more than the private sector estimates when other pay was included.

\section{Changes in 2006}

In 2006 ASHE moved to the ONS standard for geographic areas using Output Areas (OAs) as the building block to higher level geographic breakdowns. Previously, ASHE geographies were created by matching returned postcode information against the Inter Departmental Business Register to give various levels of geographic information. The key points are:

- ASHE results for geographic areas are produced in line with the ONS standard and this allows further geographic analysis variables to be produced

- The quality of geographic results has improved 
In addition, from 2006 the Labour Force Survey (LFS) has moved from using seasonal quarters to calendar quarters. As ASHE uses LFS data in the calculation of aggregation weights, it was necessary to move from using data taken from the LFS spring quarter to LFS quarter two.

The inclusion of supplementary information since 2004, the introduction of a new questionnaire in 2005, and the move to using new ONS geographies and LFS calendar quarters in 2006 has meant that the ASHE results are discontinuous in 2004. Therefore a consistent series which takes into account all of these identified changes has been produced going back to 2004. For 2004, results are also available that exclude supplementary information to be comparable with the back series generated by imputation and weighting of the 1997 to 2003 NES data.

\section{Changes in 2007}

In March 2007, ONS released information on its statistical work priorities over the period 2007-8. ONS announced that the sample size of the ASHE was to be reduced by 20 per cent. ASHE results for 2007 are based on approximately 142,000 returns, down from 175,000 in 2006 . The impact of this change was minimised by reducing the sample in an optimal way, with the largest sample reductions occurring in industries where earnings are least variable. The sample cut did not affect Northern Ireland, neither did it affect a number of organisations with an agreement to provide information electronically.

ONS also introduced a small number of methodological changes, which improved the quality of the results. These included changes to the sample design itself, as well as the introduction of an automatic occupation coding tool, ACTR.

The key benefits of moving to ACTR coding are:

- an improvement in the quality and consistency of ASHE results

- out-of-date codes will be updated annually

- ACTR provides ASHE and ONS with a standard tool for coding occupation

The methodological changes made in 2007 have been taken back to 2006, so that from 2006 to 2009 results are available on the same basis. For 2006, results are also available on the same basis as 2004 and 2005 .

Further information can be found on the National Statistics website at www.statistics.gov.uk/downloads/theme_labour/ASHE/ChangelnASHE07.pdf

\section{Changes in 2008}

In May 2008 the LFS was re-weighted to the latest (2007/08) population estimates. Previously LFS results were based on population totals published in 2003. ASHE uses LFS to calculate aggregation weights. The revised LFS figures have been used for 2007 (revised) and 2008 ASHE results. The impact of the new weights on the ASHE results for 2007 is small.

\section{Changes in 2009}

In 2009 the 1 per cent sample of employees whose employers had registered PAYE schemes was restored, following the two years in which the sample size was reduced by 20 per cent. ASHE results for 2009 are based on approximately 177,000 returns, up from 146,000 returns in 2008.

The Standard Industrial Classification (SIC) 2007 has replaced SIC 2003 as the classification used to present earnings statistics for ASHE. The first year available on the new basis is 2008. From 2009 onwards the figures will be presented on the SIC 2007 basis only.

It is also important to note that ASHE includes breakdowns by public and private sector according to the legal status of the employers. Between 2008 and 2009 Lloyds Banking Group, the Royal Bank of Scotland Group and HBOS PLC were reclassified from the private sector to the public sector. Interpretation of public / private sector movements is therefore more difficult between 2008 and 2009 than in previous years.

The proportion of part-time employees in the workforce has previously been calculated using ASHE estimates. While these estimates are suitable for indicative purposes the Labour Force Survey (LFS) provides a better measure of the composition of the workforce and as such the Patterns of Pay article will present workforce estimates based on LFS results from 2009 onwards. The supporting tables also present a back series of LFS estimates of the proportion of part-time employees in the workforce as a comparison.

\section{Definitions}

The earnings information collected relates to gross pay before tax, National Insurance or other deductions, and generally excludes payments in kind. With the exception of annual earnings, the results are restricted to earnings relating to the survey pay period and so exclude payments of 
arrears from another period made during the survey period. Any payments due as a result of a pay settlement but not yet paid at the time of the survey will also be excluded.

For particular groups of employees, changes in median earnings between successive surveys may be affected by changes in the timing of pay settlements, in some cases reflecting more than one settlement and in other cases no settlement at all.

Most of the published ASHE analyses relate to full-time employees on adult rates whose earnings for the survey pay period were not affected by absence. They do not include the earnings of those who did not work a full week, and those whose earnings were reduced because of sickness, short-time working, etc. Also they do not include the earnings of employees not on adult rates of pay, most of whom will be young people. Some more information on the earnings of young people and part-time employees is available in the detailed annual published ASHE results. Full-time employees are defined as those who work more than 30 paid hours per week or those in teaching professions who work more than 25 paid hours per week.

\section{Factors contributing to earnings growth}

The increase in average earnings from one year to the next reflects several factors; pay settlements implemented between the April survey dates; changes in the amount of paid overtime and other payments relative to basic pay; and the structural effects of changes in the composition of the ASHE sample and the employed labour force.

\section{Revisions}

In line with normal practice this article contains revised estimates from the 2008 survey results published on 14 November 2008. These take account of some corrections to the original 2008 data which were identified during the validation of the results for 2009 , as well as late returns.

\section{Other earnings information}

Average Weekly Earnings (AWE) and the Average Earnings Index (AEI), both based on the Monthly Wages and Salaries Survey of 9,000 employers, provide information on changes in mean earnings for broad industrial sectors. No information is available on occupation, paid hours worked, and other characteristics of the workforce.

The LFS collects information on the earnings and hours of about 15,000 households over each quarter. In addition it collects data on a wide range of personal characteristics, including education level and origin. This enables the preparation of statistics on levels and distribution of earnings similar to ASHE but with lower precision due to the much smaller sample size.

\section{Publication arrangements}

National averages of earnings hide wide variations between different collective agreements, industries, occupations, regions and age groups. The published tables containing the detailed annual ASHE results for the UK include analyses of each of these and are now available on the National Statistics website at

www.statistics.gov.uk/StatBase/Product.asp?vlnk=13101

Low pay estimates show the number of jobs paid below the National Minimum Wage in the UK. The estimates were produced using a methodology based solely on ASHE. Further information on the low pay methodology and detailed results are now available on www.statistics.gov.uk/StatBase/Product.asp?vlnk=5837 